\title{
"Escute, pai": diálogos entre filhos(as) e pais em canções populares brasileiras *
}

\author{
Maura Penna (DEM/UFPB, João Pessoa, PB) \\ maurapenna@gmail.com
}

\begin{abstract}
Resumo: As relações entre pais e filhos(as) configuram um tipo particular de relação entre gerações, na medida em que ocorrem no seio da família, instituição social marcada por vínculos de dependência e responsabilidade e por laços emocionais. Diversas canções que têm essas relações como tema são reunidas no CD Como nossos pais (2008), que exemplifica a tendência, também presente na indústria fonográfica, de preservação da produção musical, na medida em que apresenta diversas gravações com datas entre 1966 e 1988. Deste CD, selecionamos três canções que claramente configuram uma fala filial dirigida ao pai como interlocutor: Papai me empresta o carro (de Roberto de Carvalho e Rita Lee); Já fui (de Marina Lima e Antônio Cícero); Pai (de Fábio Jr.). Numa análise que articula contribuições da sociologia e da psicologia, mostramos como essas canções revelam diferentes momentos do processo de conquista da maturidade e da autonomia pelos jovens, com suas contradições, refletindo também as transformações sociais na configuração da família e no comportamento sexual. Discutimos, ainda, com base na tipologia proposta por TATIT, como essas canções tratam diferentemente a relação entre letra e melodia.
\end{abstract}

Palavras-chave: canção; família; relações entre pais e filhos(as); indústria fonográfica.

\section{"Listen to me, dad": dialogs between fathers and sons in Brazilian popular music}

Abstract: The relationships between parents and their children configure a specific part of the relationship between generations, as they occur on the nucleus of the family, which is a social institution linked together by dependency, responsibility and emotional bounds. Several songs which have these relationships as a theme are grouped on the album Como nossos pais (2008) (Like our parents). This album exemplifies a tendency, also present in the phonographic industry, of the preservation of musical production, as it presents several recordings from dates varying between 1966 to 1988. From this album, we have selected three songs that clearly fits the scenario of a son/daughter speaking to his/her father: Papai me empresta o carro (Dad lend me the car) (by Roberto de Carvalho and Rita Lee); Já fui (I'm gone) (by Marina Lima and Antônio Cícero); Pai (Father) (by Fábio Jr.). In an analysis that articulates contributions from sociology and psychology, we reveal how these songs show different moments of the process, with their contradictions, through which the youth conquers maturity and autonomy. We also show how these songs reflect the social transformations on the configuration of the family and sexual behavior. We also discuss, based on the typology proposed by TATIT, how these songs deal differently with the relationship between lyrics and melody.

Keywords: song; family; relationship between father and children; phonographic industry.

\section{A canção popular}

Luiz TATIT (2004) discute, em seu livro 0 século da canção, como no Brasil, durante o século XX, a canção popular se consolidou e se disseminou como uma prática artística capaz de "traduzir os conteúdos humanos relevantes em pequenas peças formadas de melodia e letra" (TATIT, 2004, p.11). A seu ver, nesse período a canção se libertou dos gêneros rítmicos predefinidos, na medida em que 0 maior compromisso passou a ser entre o modo de dizer melódico e a própria letra (TATIT, 2004, p.229):
[...] em qualquer época, precisamos celebrar os encontros, lamentar as separações, anunciar e denunciar situações, retratar o lirismo e a estética do cotidiano. Já há história suficiente na canção popular para se depreender um certo revezamento dos modos de dizer - envolvendo sempre melodia e letra - que serve justamente para contemplar esses conteúdos psicoculturais. (TATIT, 2004, p.232).

Por sua vez, Monclar VALVERDE (2008, p.270-271) critica essa concepção - tanto de Luiz Tatit quanto de José Ramos Tinhorão, outro estudioso da música popular brasileira - da canção como "um formato musical que, bem 
ou mal, simplesmente espelha a dinâmica e a estrutura da palavra falada", encontrando sua força, portanto, na "sua condição de veículo da mensagem". Contrapondo-se a este posicionamento, VALVERDE (2008) interpreta a importância adquirida pela canção como um acontecimento da história da música, enfatizando os seus aspectos propriamente musicais. Para este autor, a canção é uma forma musical típica da cultura popular urbana que se tornou "o último reduto da tonalidade". Por estar centrada na melodia, o percurso narrativo da canção é mais simples e concentrado. Além disso, a simplificação instrumental da música pop e o seu padrão de "acompanhamento" harmônico estabelecem uma relação solo-acompanhamento em que a melodia é a figura, o que "acentua ainda mais a unidade desta Gestalt temporal que é a canção e reforça o seu poder expressivo" (VALVERDE, 2008, p.271-272). 0 autor considera a canção, portanto, uma "microestrutura tonal exemplar" (VALVERDE, 2008, p.275).

Indo além, VALVERDE (2008) enfatiza diversos aspectos que são colocados em jogo através da mediação da performance do cantor:

\footnotetext{
[...] enquanto forma musical e formato midiático, a canção não se reduz ao feliz casamento entre palavra e música: a voz, pela singularidade de seu timbre, torna presente o corpo e o desempenho de alguém real; a melodia, a seu modo e sem dizer nada, conta uma história envolvente, quando não arrebatadora; o arranjo e a instrumentação datam e localizam o acontecimento que se canta, conferindo concretude e familiaridade à ficção; as palavras, enfim, formam o elo simbólico de uma comunidade de falantes que são anônimos e se desconhecem, mas se reconhecem, enquanto falantes. (VALVERDE, 2008, p.272-273 - grifos do original)
}

Assim, para VALVERDE (2008, p.275-276), a gestualidade vocal que se realiza através da canção pode ser mais importante para a adesão do ouvinte do que o conteúdo veiculado por sua letra, o que permite o envolvimento com a canção, mesmo que suas palavras estejam em uma língua que não dominamos.

Desta forma, VALVERDE (2008) não aborda apenas a canção como uma composição que articula melodia e letra, mas considera especificamente a sua realização concreta, particular, ou seja, uma determinada ocorrência da composição, aproximando-se assim da concepção de performance de ZUMTHOR (2007), que também a vincula à voz e ao corpo: "A performance dá ao conhecimento do ouvinte-espectador uma situação de enunciação" (ZUMTHOR, 2007, p.70). Entretanto, em se tratando de um registro fonográfico (como no material por nós analisado), é abolida "a presença de quem traz a voz", além de ser possivel ultrapassar o "puro presente cronológico", pois a voz gravada "é reiterável, indefinidamente, de modo idêntico" (ZUMTHOR, 2007, p.14). Na gravação não há, portanto, uma visão global da situação de enunciação, pois falta um elemento de mediação - no caso, o elemento visual (ZUMTHOR, 2007, p.69).

Mas é preciso salientar, comparativamente, que embora TATIT (1986, p.3) caracterize a canção e analise sua eficácia a partir da relação entre "o seu componente melódico e seu componente linguístico", centrandose então na composição ${ }^{1}$, ele também reconhece que: "A harmonia, o arranjo instrumental e a gravação [...] são trocados a cada versão apresentada", de modo que os "arranjos e as gravações podem produzir de novo a canção, dando-Ihe um perfil nem sonhado pelo autor" (TATIT, 1986, p.1). Deste modo,

\begin{abstract}
A canção, como a música, transcorre e só tem sentido no tempo. Ela precisa de tempo para se constituir. No entanto, mais que tudo, desafia a inexorabilidade do tempo, materializando-o em substância fônica vocal. [...] 0 núcleo entoativo da voz engata a canção na enunciação produzindo efeito de tempo presente: alguém cantando é sempre alguém dizendo, e dizer é sempre aqui e agora. (TATIT, 2002, p.20)
\end{abstract}

Como consequência, TATIT (2002, p.20), ao considerar que o embrião entoativo "reproduz a circunstância de enunciação a cada execução", aproxima-se em certa medida da noção de performance de ZUMTHOR (2007) acima discutida e, através dela, da abordagem de VALVERDE (2008), cuja concepção valoriza mais o caráter musical da canção.

No âmbito deste trabalho, enfatizamos, como TATIT (2004), a relação entre melodia e letra, mas tomando as canções selecionadas na especificidade das gravações apresentadas no CD Como nossos pais (FAOUR, 2008), cujas características diferenciais abordamos adiante. Por conseguinte, num primeiro momento, considerando os textos verbais - as letras - como narrativas, analisamos como retratam as relações entre pais e filhos(as), que configuram um tipo particular de relação entre gerações. Num segundo momento, discutimos como essas canções tratam diferentemente a relação entre letra e melodia, com base nos processos de tematização, figurativização e passionalização (cf. TATIT, 1986, 2002, 2004).

\section{Gerações e famílias}

Dentre os vários significados do termo "geração", apresentados pelo Dicionário eletrônico Houaiss da língua portuguesa, encontramos: "ação ou efeito de gerar(-se)" e "função pela qual um ser organizado produz outro semelhante; procriação, germinação". Por extensão de sentido, temos ainda "grau de filiação em linha direta"; "tronco familiar, grupo racial; ascendência, estirpe, genealogia" - dentre outras acepções.

Com base nesses sentidos de "geração", podemos pensar a família como uma instituição social que organiza e legitima a procriação. "A família é sempre um resultado das relações sexuais passadas ou correntes: sem sexo não há família" - como indica THERBORN (2006, p.12). Ao mesmo tempo, ela regula as relações sexuais, "determinando quem pode e quem deve ou não ter relações sexuais com quem". No entanto, não existe um modelo único e universal de família, embora ela seja correntemente vista como uma instituição que contribui para a perpetuação da ordem social.

Diante da existência de sociedades com práticas sexuais e matrimoniais bastante diferenciadas, o antropólogo LÉVI-STRAUSS (1980, p.14) considera a família como 
"uma das questões mais escorregadias dentro do estudo da organização social", de modo que não deve ser tratada de forma dogmática. Para o autor, a família pode ser definida como um grupo social que apresenta as seguintes características:

1) Tem sua origem no casamento. 2) É formado pelo marido, pela esposa e pelos filhos(as) nascidos do casamento, ainda que seja concebivel que outros parentes encontrem o seu lugar junto do grupo nuclear. 3) Os membros da familia estão reunidos por a) laços legais, b) direitos e obrigações econômicas, religiosas e de outro tipo, c) uma rede precisa de direitos e proibições sexuais, além duma quantidade variável e diversificada de sentimentos psicológicos tais como amor, afeto, respeito, temor, etc. (LÉVISTRAUSS, 1980, p.16)

Nesta definição, a instituição do casamento - que pode ter diferentes formas, a depender da cultura - é um componente essencial. Já GIDDENS (2005, p.151) define a família como "um grupo de pessoas diretamente unidas por conexões parentais, cujos membros adultos assumem a responsabilidade pelo cuidado das crianças", procurando, assim, contemplar as transformações que ocorrem nas sociedades ocidentais contemporâneas onde é grande a diversidade de formas de famílias e de núcleos domésticos, inclusive no tocante a divórcios, recasamentos, coabitação, assim como a núcleos familiares monoparentais ou construidos a partir de parcerias homossexuais. Desta forma, não se prendendo mais à instituição do casamento, a conceituação de família enfatiza a importância da relação intergeracional, o que salienta o papel da mesma na reprodução, na educação infantojuvenil e na socialização.

Por outro lado, o Dicionário eletrônico Houaiss da língua portuguesa traz ainda, como significados da palavra "geração", por extensão de sentido: "conjunto de pessoas que têm aproximadamente a mesma idade" e "espaço de tempo correspondente ao intervalo que separa cada um dos graus de uma filiação e que é avaliado em cerca de 25 anos". Isto indica que, apesar dos vínculos de apoio à geração mais jovem, dentro da família, há uma distância e/ou uma oposição entre gerações, na medida em que existe potencialmente a referência ao grupo com a mesma idade fora do núcleo familiar.

Nesse trânsito entre a família - a primeira unidade social em que vivemos, nosso primeiro campo de socialização - e o "mundo lá fora" - a começar pela escola - que nos traz novas referências, crescemos e nos tornamos autônomos, adultos responsáveis, capazes de, por nossa vez, assumir a responsabilidade pelo cuidado das crianças em novas famílias. Pois desta forma as sociedades humanas se renovam e se preservam, passando suas tarefas de geração a geração.

Como diz LÉVI-STRAUSS (1980, p.16) na citação anteriormente apresentada, os membros da família estão reunidos tanto por "direitos e obrigações econômicas, religiosas" ou de outra ordem, quanto por uma "quantidade variável e diversificada de sentimentos psicológicos tais como amor, afeto, respeito, temor, etc". Assim, do ponto de vista psicológico e da formação da personalidade, esse processo de tornar-se adulto e ser capaz de construir novas famílias depende das próprias relações familiares que contextualizaram - melhor dizendo, constituíram - a nossa formação.

Aos vinte, ou trinta e poucos anos, somos amantes, trabalhamos, somos amigos. Somos parceiros num casamento, pais dos nossos filhos. Mas continuamos também a ser, sob ângulos que talvez não nos convenham mais, filhos dos nossos pais.

Pois nossa família, nossa primeira família, foi o cenário onde nos tornamos indivíduos à parte. Foi também a primeira unidade social

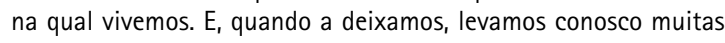
das suas tendências formativas. Ficamos ligados a ela interiormente, por mais que tentemos nos libertar. E a maioria das pessoas - mesmo que de modo distante, obrigatório e rotineiro - fica ligada a ela também externamente.

Porém, mesmo mantendo a conexão - a conexão interna, a conexão externa -, continuamos a lutar para nos libertar dessa primeira família. Aprendemos a ver o mundo com nossos olhos, e não com os dos nossos pais. (VIORST, 1999, p.229)

Num processo marcado por contradições, na oscilação entre vínculos e rupturas, os jovens - os filhos(as) - conquistam sua autonomia e, por sua vez, podem se tornar pais/ mães. Por tudo isso, fica claro que as relações entre pais e filhos(as) configuram um tipo particular de relação entre gerações, na medida em que ocorrem no seio da família, instituição social marcada tanto por vínculos de dependência e responsabilidade, quanto por laços emocionais.

\section{0 CD temático Como nossos pais e o mercado fonográfico}

Argumentando que a atuação do mercado fonográfico não é tão simples e homogênea como pode parecer, TATIT (2004, p.231-232) discute como, ao lado do investimento em "lançamentos explosivos" - e efêmeros -, há também uma preocupação com a diversidade e com a preservação de gêneros, estilos, atuações e mesmo artistas:

\footnotetext{
Tudo ocorre como se o mundo financeiro, em interação com o mundo artístico, captasse e ao mesmo tempo influenciasse um ritmo de alternância cultural que serve para manter vivas e atuantes todas as dicções (modos de compor e de cantar) que formam o universo musical da nossa sociedade. Em outras palavras: não se pode cultivar um só gênero ou uma só dicção por muito tempo pois a sociedade é complexa e precisa dos gêneros e dicções abandonados para se reconhecer integralmente. (TATIT, 2004, p.232)
}

Como uma das estratégias que exploram essa permanência, TATIT (2004, p.246) aponta, nos anos de 1990, as regravações de antigos sucessos: desde "relançamentos de antigos LPs em formato de CD até as compilações dos melhores momentos da carreira, passando pelos Songbooks e pelas reinterpretações de clássicos do cancioneiro nacional e internacional".

Também agrupando repertório já consagrado, O CD Como nossos pais (FAOUR, 2008), de caráter temático, produzido pela Som Livre em 2008, foi idealizado pelo jornalista, crítico e pesquisador musical - que também 
atua como escritor e produtor musical - Rodrigo Faour, também responsável pela seleção de repertório e pelos textos do encarte. Como informa a biografia disponivel em seu site pessoal, Faour tem trabalhado "no processo de revitalização do acervo das principais gravadoras brasileiras (Universal, SonyBMG, EMI, Warner e Som Livre), produzindo compilações e reedições de álbuns importantes da música brasileira, sempre acompanhados de textos explicativos assinados por ele"2. Sem dúvida, a coletânea Como nossos pais (FAOUR, 2008) relaciona-se com este trabalho: ela reúne gravações de vários intérpretes, com datas entre 1966 e 1988, a partir de fonogramas cedidos pela SonyBMG, EMI, RGE e Universal - como informa o encarte do CD.

Neste ponto, vale ressaltar que tomamos o CD como um objeto cultural não estritamente musical ou sonoro, pois imagens e textos verbais escritos, presentes no encarte, também o integram e são por nós considerados. E o encarte traz, em sua contracapa, um texto de apresentação assinado por seu idealizador, que assim se inicia:

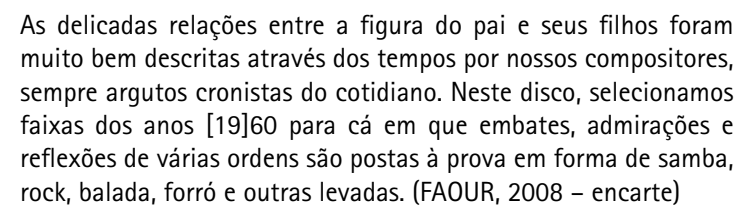

Dedicado por FAOUR (2008 - encarte) ao próprio pai, a caracterização deste $C D$ como uma manifestação da preservação ou permanência da produção musical, acima discutida por TATIT (2004), evidencia-se por um certo olhar para trás na história, que também se revela nas ilustrações da capa do disco, com base em fotos de diversas épocas - pertencentes a acervos pessoais, conforme agradecimento no encarte - que retratam pais e filhos(as) em diversas faixas etárias. Tais fotos são evidentemente antigas, como também as gravações reapresentadas no $C D$ em questão, pois a mais recente data de vinte anos antes da produção da coletânea. Isso também reforça a colocação de TATIT (2004, p.232) quanto à preservação de diversos modos de compor e de cantar (que chama de "dicções") que fazem parte do universo musical de nossa sociedade.

Pela importância de evidenciar tais questões, especificamos as 14 canções reunidas no $C D$, com as referências de autoria e intérprete, além dos dados da gravação original:

1. Coisinha do pai (de Jorge Aragão/ Almir Guineto/ Luiz Carlos) - intérprete Beth Carvalho - gravação original do LP "No pagode" (RCA Victor, 1979)

2. Papai vadiou (Rody do Jacarezinho/ Gaspar do Jacarezinho) - Leci Brandão - do LP "Leci Brandão" (Copacabana, 1985)

3. O mundo é um moinho (Cartola) - Cazuza - do LP "Cartola bate outra vez" (Som Livre, 1988)

4. Como nossos pais (Belchior) - Elis Regina - do LP "Falso brilhante" (Philips, 1976)

5. Avôhai (Avô e pai) (Zé Ramalho) - Zé Ramalho - do LP "Zé Ramalho" (Epic/CBS, 1978)
6. Papai me empresta o carro (Roberto de Carvalho/ Rita Lee) - Rita Lee - do LP "Rita Lee" (Som Livre, 1979)

7. Já fui (Marina Lima/ Antônio Cícero) - Marina Lima - do LP "Todas" (PolyGram, 1985)

8. Pai (Fábio Jr.) - Fábio Jr.- do LP "Fábio Jr." (Som Livre, 1979)

9. Naquela mesa (Sérgio Bittencourt) - Nelson Gonçalves - do LP "Passado e presente" (RCA Victor, 1974)

10. 14 anos (Paulinho da Viola) - Paulinho da Viola - do LP Élton Medeiros e Paulinho da Viola "Samba na madrugada" (RGE, 1966)

11. Espelho (João Nogueira/ Paulo César Pinheiro) João Nogueira - do LP "Espelho" (EMI-Odeon, 1977)

12. De pai pra filha (Martinho da Vila) - Martinho da Vila - do LP "Verso... Reverso" (RCA Victor, 1982)

13. Herança de meu pai (Benício Guimarães) - Jackson do Pandeiro - do LP "Isso é que é forró" (Polyfar/ Philips, 1981)

14. Papai sabe-tudo (Leo Jaime/ Leandro) - Erasmo Carlos - do LP do especial infantil "Plunct, Plact, Zuuum 2" (Som Livre, 1984) ${ }^{3}$

Como o próprio texto do encarte esclarece, apesar do título Como nossos pais (FAOUR, 2008) - que permite remeter também à figura materna -, a intenção é homenagear os pais - figuras paternas, masculinas. Mas é preciso contextualizar essa homenagem e essa centralidade da figura masculina na relação com os filhos, nas canções do $C D$, diante das transformações sociais da família no mundo atual. Como discutem CAVALCANTI e MELO (2008), na organização da sociedade brasileira, com as suas especificidades, há uma "grande variedade de 'famílias alternativas', de relacionamentos com outras configurações, diversidades de classes, de etnias, etc". Neste sentido, o número de famílias chefiadas por mulheres em nosso país cresceu $30 \%$ na última década, atingindo a marca de 14,6 milhões de lares, de acordo com o Instituto Brasileiro de Geografia e Estatística (IBGE). Na imensa maioria desses lares, a mulher é divorciada ou o pai abandonou a família (VALADARES, 2005, p.61).

Um texto sobre a coletânea, disponível no site de Rodrigo Faour e também assinado por ele, assim apresenta o disco:

Este CD mostra as relações de pai \& filho/filha vistas pela lente da MPB de várias fases e vertentes. Pelo viés do respeito ou do humor, nas mais diversas situações - das mais corriqueiras às saias mais justas (ou seriam calças?). Temos aqui os conselhos paternos, a admiração por seus ensinamentos, a superproteção, as broncas mútuas, a saudade do pai que se foi, o encanto do pai com os filhos pequenos e o mesmo atrapalhado em cuidar deles sozinho... Enfim, uma bela história contada em forma de disco ${ }^{4}$.

Muitas dessas músicas, no entanto, falam sobre os pais ou sobre sua relação com seus filhos ou filhas, mas não chegam a explicitar um caráter dialógico, como é o caso da conhecida canção Naquela mesa (BITTENCOURT, 2008), composta pelo filho do músico e compositor Jacob do Bandolim, que canta a saudade do pai: "Naquela mesa tá faltando ele / E a saudade dele tá doendo em mim". 
Para nossa análise, selecionamos três canções que claramente configuram uma fala filial dirigida ao pai como interlocutor, pois falam com o pai: Papai, me empresta o carro, de Roberto de CARVALHO e Rita LEE (2008); Já fui, de Marina LIMA e Antônio CíCERO (2008); Pai, de FÁBIO Jr.(2008). Mesmo que não tenhamos, aqui, a fala do pai como resposta, suas letras pressupõem o diálogo e, potencial e intencionalmente, esperam uma resposta. Procuramos, então, discutir como essas três canções revelam diferentes momentos do processo de conquista da autonomia pelos jovens, com suas contradições: os vínculos afetivos, a dependência, a repressão, a rebeldia, o desejo de assumir a própria vida e a própria sexualidade; tornar-se adulto e, por sua vez, pai.

\section{Três momentos/movimentos na relação pai-filhos(as)}

Os filhos que falam com seus pais nas três canções escolhidas não são mais crianças, mas sim jovens (adolescentes ou adultos) em diferentes momentos do seu processo de construção da individualidade - ou seja, no processo de se tornar indivíduos à parte, nos termos de VIORST (1999, p.19) -, de conquista da independência e da autonomia.

Em Papai, me empresta o carro (CARVALHO; LEE, 2008), um rapaz que ainda mora com a familia - "aqui em casa é impossivel namorar" - e é dependente dela, inclusive financeiramente, pede o apoio do pai para levar a sua "garota" ao cinema e "tirar um sarro". Apesar de cantada pela voz feminina da roqueira Rita Lee, o enunciador é claramente seu alter-ego masculino, pois, como mostra MAINGUENEAU (1996, p.85), nem sempre há coincidência entre 0 "produtor físico do enunciado (o indivíduo que fala ou escreve)" - no caso, a cantora - e a categoria do "eu", aquele que se coloca como enunciador - seu alter-ego.

\author{
Papai, me empresta o carro \\ Papai, me empresta o carro \\ Tô precisando dele pra levar \\ Minha garota ao cinema \\ Papai, não crie um problema \\ Não tenho grana pra pagar um motel \\ Não sou do tipo que frequenta bordel \\ Você precisa me quebrar esse galho \\ Então, me empresta o carro \\ Papai, me empresta o carro \\ Pra poder tirar um sarro com meu bem! (CARVALHO; LEE, 2008)
}

Gravada originalmente no final da década de 1970, a canção revela uma configuração tradicional de família nuclear e patriarcal -, onde o pai desempenha claramente a função "instrumental" de provedor. Desta forma, é aqui retomada a visão da família nuclear como a unidade mais bem equipada para lidar com as demandas da sociedade industrial, defendida pelo sociólogo funcionalista Talcott Parsons. Nessa "família convencional", a especialização de funções determina que um adulto pode trabalhar fora de casa enquanto o outro adulto cuida da casa e dos fiIhos: enquanto o marido/pai atua como provedor, a muIher/mãe cumpre a função "afetiva", emocional, dentro do ambiente doméstico. Por tratar tal divisão de tarefas domésticas como natural e inquestionável, a concepção de Parsons de família é atualmente considerada ultrapassada (GUIDDENS, 2005, p.152-153).

Por outro lado, no entanto, essa canção também reflete a "revolução sexual" que ocorreu no mundo ocidental, no último terço do século $X X$, impulsionada por inovações tecnológicas que permitiram dissociar sexo de procriação:

\footnotetext{
Em primeiro lugar, em termos culturais e legais, houve uma secularização da sexualidade, libertando-a de regras religiosas ou de quaisquer outras normas aprioristicas que a considerassem "pecaminosa" ou condenável de algum modo, quando exercida fora do casamento e por puro prazer, sem intenção de procriação. [...] A revolução real foi, é claro, a prática em si mesma. Ela se manifestou claramente em mais iniciações sexuais pré-maritais, em idades mais jovens. Ao passo que a idade do casamento aumentou, a idade da primeira relação sexual diminuiu. A prática de sexo pré-marital ampliou-se de forma significativa. (THERBORN, 2006, p.306-307)
}

Apesar de a expressão "tirar um sarro" poder ser tomada de forma mais branda, há outras indicações - como as referências ao motel e ao bordel - da aceitação do sexo prémarital. Por outro lado, pelo caráter patriarcal da família representada e pela tradição machista de nossa sociedade, é possivel também considerar que tal aceitação poderia se limitar aos filhos do sexo masculino: o pai teria orgulho de incentivar as manifestações de masculinidade de seu filho rapaz, que assim prova que "já é um homem". A mesma liberalidade talvez fosse questionada, portanto, em relação às filhas mulheres. Neste sentido, apesar de a canção ter um enunciador masculino, a voz feminina de Rita Lee, pela singularidade de seu timbre, torna presente o corpo e o desempenho de uma mulher real, como indicam tanto VALVERDE (2008, p.272 - trecho acima citado) quanto ZUMTHOR (2007, p.83-85), para quem a voz "possui plena materialidade", estabelecendo "uma relação de alteridade que funda a palavra do sujeito". Desta forma, a performance da cantora coloca em cena a dimensão feminina e, em certa medida, a postura feminista: a mulher reivindicando seus direitos e sua liberdade.

Na canção, a afirmação de masculinidade do filho é também compartilhada pelo pai, que com a mesma idade também "pintava o sete", revelando-se assim uma tradição familiar: tal pai, tal filho; ou filho de peixe, peixinho é.

Papai eu não fumo,

Papai eu não bebo,

Meu único defeito é não ter medo

De fazer o que gosto, u-hu!

Papai eu aposto

Na minha idade você pintava o sete

Mamãe tem ódio de uma tal Elizete

Aqui em casa é impossivel namorar

Então qual é a sua?

Eu só quero um sarro

Meia hora no seu carro com meu bem! (CARVALHO; LEE, 2008)

Se vinculado à família e de certa forma reproduzindo seus valores, inclusive provando ser um bom filho - que não fuma e não bebe -, o jovem rapaz reafirma sua in- 
dividualidade - pois não tem medo de fazer o que gosta, o que pode ser visto como um "defeito", pelo pai -, fortalecendo-se no processo de conquista de autonomia, preparando-se para o momento de deixar o lar.

Esse momento de despedida e, em certa medida, de ruptura é retratado na canção Já fui (LIMA; CICERO, 2008), gravada originalmente por Marina Lima em LP de 1985:

\author{
Tchau, coroa! \\ Tchau, tchau, cara! \\ Sim, o tempo voa \\ Sou mulher já! \\ Tem alguém à espera \\ Que vai ficar uma fera \\ Se eu demorar demais \\ Tem essa fissura \\ Tem minha loucura \\ Tem a de vocês \\ Vocês sabem que eu os amo \\ E muito \\ Mas, com licença, eu vou à luta \\ Sem limite \\ Pois se a Terra é mesmo fruta \\ Eu tenho apetite (LIMA; CICERO, 2008)
}

A interjeição (tchau) com que a letra se inicia, sendo logo repetida - e que irá também encerrar a canção marca claramente a despedida, o momento em que a filha deixa o lar. No entanto, é interessante notar que seu sentido dicionarizado não é de adeus, mas sim de até logo, até a vista ${ }^{5}$, o que indica que, embora assumindo suas escolhas e sua própria vida, a filha reconhece $e$ pretende manter os vínculos com os pais: "vocês sabem que eu os amo". O jogo com as palavras cara e coroa os dois lados de uma moeda, mas também tratamento informal dado a pessoas próximas - permite inferir que a filha se dirige ao casal: ao pai (cara) e à mãe (coroa). Mais uma vez, a configuração familiar é nuclear.

Reafirmando a sua individualidade e o direito às suas escolhas, a filha declara: "com licença, eu vou à luta". Aqui, há uma clara relação intertextual com o título do livro autobiográfico de Eliane Maciel, publicado no final da década de 1970 com bastante repercussão, sendo uma referência corrente, portanto, na época em que o LP de Marina foi lançado, e pouco depois, em 1986, a obra foi adaptada para o cinema ${ }^{6}$. Assim, a filha - que podemos supor que conquistou alguma independência financeira, inclusive - sai de casa e vai à luta para buscar suas verdades, para atender a seus anseios, seus desejos - sua "fissura", sua "loucura" -, num processo que é também uma luta para se libertar da família e aprender a ver o mundo com seus próprios olhos. "Pois o ato de sair de casa só se torna uma realidade emocional quando deixamos de ver o mundo com os olhos de nossos pais", como discute VIORST (1999, p.233).

"Sou mulher já!", diz a filha. E isto não tem apenas o sentido de "não sou mais criança", mas também de maturidade sexual, pois "tem alguém" que a está esperando e ela vai embora "com seu amor", como a segunda parte da letra explicita. Encontramos aqui também, portanto, um reflexo da "revolução sexual" das últimas décadas do século $X X$, com indicações de mudanças comportamentais também para as mulheres. "Mais do que qualquer coisa, a revolução sexual tornou o longo período de sexo pré-marital e a pluralidade de parceiros sexuais durante a vida um fenômeno 'normal', tanto no sentido estatístico quanto no moral" (THERBORN, 2006, p.310).

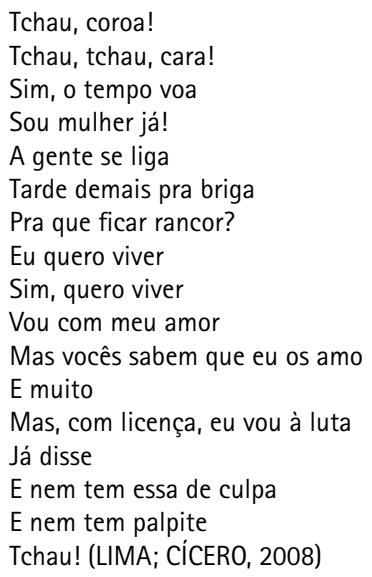

Retomando questões já apresentadas na primeira parte da canção, a segunda parte traz elementos que revelam as tensões e dificuldades de todo esse processo, através das referências a brigas, rancor, culpa... Como diz GIDDENS (2005, p.166), "a vida familiar circunscreve praticamente todo o campo de experiência emocional". Pois a família tanto apóia a criança em seu processo de vida, quanto a reprime; e os filhos podem se acomodar e também se rebelar. Convém lembrar que não é fácil se tornar "indivíduo à parte", adulto autônomo, capaz de se autogovernar. Neste processo de amadurecimento pessoal e social, intelectual e emocional, neste processo de conquista da liberdade individual, nossas escolhas não precisam ser ou de desafio ou então de obediência em relação aos nossos pais: "A separação não exige que os repudiemos. Exige escolhas livres" (VIORST, 1999, p.234-235).

Já em Pai (FÁBIO Jr., 2008), um filho independente e mais velho - por sua vez já pai - reavalia a sua relação com seu pai e busca meios de reconstruir os vínculos afetivos, depois de ambos terem se distanciado, física e/ou emocionalmente.

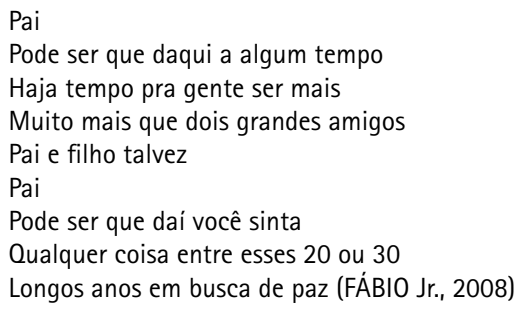

Não é clara a razão do distanciamento entre os dois: se é o caso de um "pai ausente", pelo papel de provedor ou por alguma forma de abandono do lar, por separação ou divórcio (cf. GIDDENS, 2005, p.161). Até mesmo a possibilidade de o pai ter falecido se insinua na sequência, no pedido para que renasça, ao mesmo tempo em que ele 
é convidado a partilhar de atividades cotidianas - como jantar ou brincar -, o que fortalece a ideia de que esse renascimento seja simbólico.

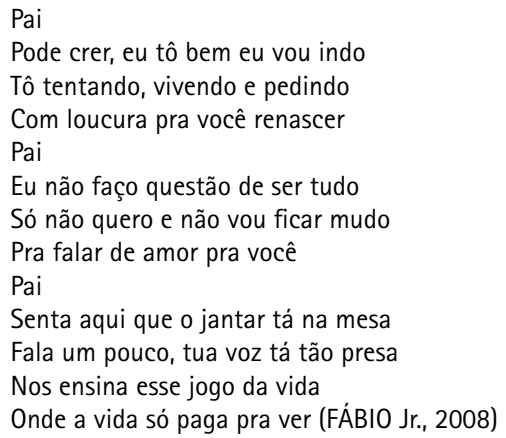

0 filho, que tenta resgatar os laços afetivos com o pai, não quer mais reprimir nem esconder seus sentimentos, e ao mesmo tempo reconhece a experiência do pai e a sua capacidade de aconselhar e ajudar. No entanto, também reafirma sua própria autonomia, na medida que não é mais a criança cujos medos eram superados no colo do pai. Porém, mesmo assim, quer o contato, quer o afeto de "recostar no peito".

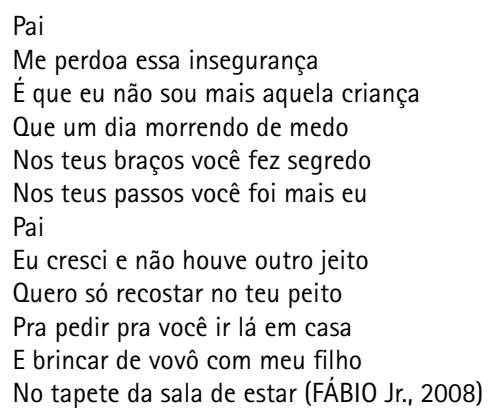

E se ele não é mais criança, pois cresceu - como é inevitável na vida -, o seu filho ainda é criança, e desse modo o afeto buscado pode ser encontrado na relação avô e neto.

[..] o fato de nos tornarmos pais ou mães pode atuar como uma reconciliação, destinando aos nossos pais melhores papéis, libertando-os para que sejam - como avô e avó - mais amorosos, pacientes e generosos do que foram como mãe e pai. Não mais preocupados em instilar valores morais, não mais encarregados da disciplina e das regras, não mais responsáveis pela formação do caráter, assumem o que há de melhor neles, e nós - felizes com tudo o que podem oferecer aos nossos filhos - começamos a perdoar os pecados deles, reais ou imaginários. (VIORST, 1999, p.235-236 - grifos nossos)

Então, esse filho que se tornou pai pode, a partir desse novo papel, dimensionar melhor a sua própria relação com seu pai - seu herói e seu bandido -, marcada pela ambivalência, pelos sentimentos conflitantes de amor e ódio.

Pai

Você foi meu herói, meu bandido

Hoje é mais, muito mais que um amigo

Nem você nem ninguém tá sozinho

Você faz parte desse caminho

Que hoje eu sigo em paz

Pai, paz (FÁBIO Jr., 2008)
Como mostra VIORST (1999, p.235), alterando antigas perspectivas da infância do indivíduo, tornar-se pai pode ser uma fase construtiva do desenvolvimento, contribuindo para uma visão mais compreensiva das relações familiares e para a cicatrização de velhas feridas. Deste modo, o pai pode tornar-se "mais que um amigo", sendo possível, então, seguir em paz o próprio caminho.

\section{Distintos tratamentos da relação entre letra e melodia}

Entendendo que a canção tem profundo vínculo com a fala - tendo nela até mesmo a sua origem -, TATIT (2002, p.11-12) enfoca "a canção como produto de uma dicção" e passa a estudar a "fala camuflada em tensões melódicas". A fala cotidiana, o discurso oral, as coisas ditas de um indivíduo a outro são sonoridades com caráter puramente utilitário, destinadas a desaparecer. Ao se tornarem canções, no entanto, entram em outra dimensão.

A instabilidade e imprecisão das entoações de nossa fala cotidiana indicam, entre outras coisas, que elas não foram criadas para resistir ao tempo, a menos que sejam transformadas em algum projeto melódico digno de preservação. Trata-se justamente do que ocorre com as canções: suas melodias são inspiradas nos contornos da fala, mas acabam adquirindo um "sentido musical" - ou seja, uma direção estabilizada por leis de condução - que, este sim, merece ser perenizado. (TATIT, 2004, p.123)

Assim, em diversas obras (cf. TATIT, 1986, 2002, 2004) trata dos "tipos de compatibilidade entre melodia e letra" (TATIT, 2004, p.76), destacando os processos de figurativização, tematização e passionalização.

Interessante notar que as três canções aqui estudadas exemplificam esses processos. Já analisamos como cada uma expressa uma relação distinta com o pai, um modo de se dirigir a ele, na medida em que refletem diferentes momentos no processo de amadurecimento pessoal do jovem, implicando em mudanças na sua relação com a familia e, especificamente, com o pai. Mas cada uma dessas canções também trata diferentemente a relação entre letra e melodia.

0 processo de figurativização é o que mais explicita a relação básica da canção com a fala coloquial, fazendo uso de recursos que visam mostrar que "a situação locutiva, criada por uma determinada canção, é viável e poderia estar acontecendo durante o tempo e o espaço de sua execução" (TATIT, 1986, p.25).

Na medida em que configuram uma fala filial dirigida ao pai, as três canções analisadas fazem uso do processo de figurativização, que sugere "ao ouvinte verdadeiras cenas (ou figuras) enunciativas". Todas elas fazem uso, por exemplo, de vocativos - papai; cara, coroa; pai - que contribuem para presentificar o tempo e o espaço da voz que canta (TATIT, 2002, p.21).

Pela figurativização captamos a voz que fala no interior da voz que canta. Pela figurativização, ainda, o cancionista projeta-se na 
obra, vinculando o conteúdo do texto ao momento entoativo de sua execução. Aqui, imperam as leis de articulação linguistica, de modo que compreendemos o que é dito pelos mesmos recursos utilizados no colóquio. (TATIT, 2002, p.21)

No entanto, em Papai me empresta o carro (CARVALHO; LEE, 2008) e Pai (FÁBIO Jr., 2008), que são musicalmente contrastantes, esse processo de figurativização se articula a outros recursos musicais de estabilidade melódica ${ }^{7}$. Na primeira, predomina a tematização e, em Pai, o processo de passionalização.

0 instrumental característico do rock, o caráter rítmico da canção e a interpretação animada e enérgica de Rita Lee evidenciam a prevalência da tematização em Papai me empresta o carro (CARVALHO; LEE, 2008), processo que sustenta as "canções aceleradas, centralizadas no refrão e repletas de recorrências melódicas", que estimulam o movimento corporal e a dança (TATIT, 2004, p.62-63).

\footnotetext{
A forma acelerada de estabilização melódica privilegia os acentos e, portanto, as vogais salientes e breves, entre as quais percutem intensamente as consoantes. Essas caracteristicas favorecem a constituição de células rítmicas bem definidas que vão se agrupando num processo denominado tematização. (TATIT, 2004, p.43 - grifo do original)
}

Já a passionalização se caracteriza como a forma desacelerada de estabilização, que valoriza o percurso melódico em seus desdobramentos progressivos.

\footnotetext{
A dominância da passionalização desvia a tensão para o nivel psíquico. A ampliação da frequência e da duração valoriza a sonoridade das vogais, tornando a melodia mais lenta e contínua. A tensão de emissão mais aguda e prolongada das notas convida o ouvinte para uma inação. Sugere, antes, uma vivência introspectiva de seu estado. Daqui nasce a paixão que, em geral, já vem relatada na narrativa do texto. Por isso, a passionalização melódica é um campo sonoro propício às tensões ocasionadas pela desunião amorosa ou pelo sentimento de falta de um objeto de desejo. (TATIT, 2002, p.23)
}

Embora não se refira ao amor sensual, a canção Pai (FÁBIO Jr., 2008) é marcada pelo alto envolvimento emocional na relação com o pai. Como analisamos na seção anterior, com base na letra, o enunciador é um filho já adulto que, depois de ter se distanciado física e/ou emocionalmente de seu pai - um estado disjuntivo, portanto, nos termos de TATIT (1986, p.26-27) -, busca os meios de reconstruir os vínculos afetivos, ou seja, busca um novo "estado de conjunção", que permita recobrar o equilibrio. 0 processo de passionalização também se evidencia pela emotividade da interpretação vocal de Fábio Jr.- própria de um "cantor romântico" -, articulada a um acompanhamento instrumental que progressivamente se enriquece e se torna mais denso, mas sempre deixando a voz em primeiro plano. Desta forma, constrói-se gradativamente um clímax sonoro, através do crescendo em intensidade, densidade e expressividade emotiva. Ressalte-se, inclusive, que a intensidade constitui "um parâmetro de dosagem do afeto investido", como diz TATIT (2002, p.15). Em comparação com o rock de Rita Lee, esta canção explora muito mais as variações - e mesmo os contrastes - de dinâmica. Desta forma, portanto, busca-se que o ouvinte se emocione com a canção.

Por sua vez, é em Já fui (LIMA; CÍCERO, 2008) que se encontram menos presentes os recursos de concentração temática ou de expansão passional dos contornos: há pouca reiteração ou sustentação vocálica. É apresentada "a voz do enunciador dizendo algo considerado oportuno" (TATIT, 2004, p.77), no caso a filha falando diretamente com os pais em tom de despedida e, em certa medida, de desafio. 0 canto é lento e pausado, e embora em alguns momentos se mostre mais expressivo, não chega a construir uma continuidade melódica que progressivamente leve a um crescendo de expressão emotiva, como acontece em Pai. 0 acompanhamento instrumental comedido, que não chega a criar uma base rítmica capaz de estimular corporalmente, deixa a voz constantemente em primeiro plano para apresentar 0 que tem a dizer. É apenas na ausência da fala que os encadeamentos rítmicos e harmônicos dos instrumentos ganham importância e se expandem - entre as partes da letra e especialmente ao final, quando se combinam com a voz (já sem texto) que explora, inclusive expressivamente, vocalizes e a interjeição tchau (cuja função entoativa veremos a seguir).

Nesta canção (LIMA; CíCERO, 2008), portanto, a figurativização é o processo predominante, atuando na criação de uma cena enunciativa que se apresenta, aqui e agora, como viável. Neste processo, além da função dos vocativos "cara" e "coroa" (acima mencionada), cabe destacar o papel da interjeição "tchau" - cuja importância para marcar o momento em que a filha deixa o lar já foi discutida na seção anterior. Aqui, convém ressaltar que a interjeição constitui um verdadeiro nó "de entrelaçamento do texto com a melodia", pois esse som vocal "não é nem bem um texto nem bem uma melodia. É uma unidade entoativa por excelência, com valor, ao mesmo tempo, musical e linguístico" (TATIT, 1986, p.23).

Retomando, agora, a citação de TATIT (2004, p.232) apresentada no início do texto, podemos constatar que as três canções analisadas exemplificam o revezamento, presente na história da canção popular, de modos de dizer - envolvendo sempre melodia e letra e os diferentes modos de tratar a relação entre elas - que serve justamente para contemplar os conteúdos psicoculturais relativos às relações afetivas e familiares.

Se as diferentes dicções que formam o universo musical da nossa sociedade dizem respeito aos modos de compor e de cantar, é interessante notar que as gravações das canções selecionadas são realizadas por seus compositores (pelo menos um deles). TATIT (2002, p.13) apresenta o fato de os compositores se tornarem naturalmente cantores - "Afinal, a voz que fala é a voz que canta" - como um elemento que reforça sua concepção de que a canção popular tem sua origem na fala. No 
caso em estudo, isto permite pressupor que as realizações específicas analisadas - o arranjo e a gravação são suficientemente fiéis à composição.

\begin{abstract}
"Arranjos e gravações trabalhadas podem não só intensificar a compatibilidade entre os componentes [letra e melodia] como também podem criar outros graus de adequação e outros espaços de compatibilidade". [...] Cabe apenas a constatação de que os trabalhos de arranjo e gravação mais bem sucedidos, em nível de eficácia da comunicação, têm sido aqueles que aproveitam a compatibilidade já existente [na composição] entre o texto e a melodia e a valorizam, aumentando a cumplicidade com o ouvinte. (TATIT, 1986, p.63)
\end{abstract}

\section{Considerações finais}

As três canções analisadas, que trazem uma fala filial dirigida ao pai como interlocutor, integrantes de um $C D$ temático datado de 2008 - que exemplifica a estratégia mercadológica de investir também na permanência -, tiveram gravações originais há mais de 20 anos. No entanto, mostram-se ainda representativas das relações entre filhos(as) e pais, relações inter-geracionais que se desenvolvem no interior da família, com grande peso emocional. Como aponta GIDDENS (2005, p.170), apesar da enorme variação de relacionamentos sociais e sexuais nas sociedades ocidentais contemporâneas, a familia continua sendo uma instituição firmemente estabelecida, ainda que submetida a grandes tensões. Pois as crianças das gerações mais novas sempre precisarão ser cuidadas, e, do ponto de vista psicológico, os pais homens têm um papel específico e importante a desempenhar no desenvolvimento da criança - e, por extensão, da pessoa:
Como destruidores construtivos da unidade mãe-filho. Como fomentadores da autonomia e da individuação. Como modelos de masculinidade para os filhos. Como confirmação da feminilidade para as filhas. E como a figura outra-que-não-a-mãe que fornece uma segunda fonte de amor constante. [...] E quando não temos pai, sentimos sua falta. (VIORST, 1999, p.77)

Contemplando conteúdos psicoculturais ainda presentes - por serem, até certo ponto, questões existenciais - tais canções podem permanecer, sendo retomadas e mantendo-se significativas. Deixam, assim, o seu recado.

Entretanto, "utilizar cada composição para deixar um recado de ordem existencial, conceitual, comportamental, enfim, essencial, representa um outro modo de encarar a melodia e, consequentemente, de se relacionar com a letra" (TATIT, 2004, p.230). Nesse outro modo, sem estar mais preso aos gêneros rítmicos predefinidos, "em vez de produzir um samba, um blues, um baião ou um rock, o compositor propunha diretamente um modo de dizer melódico que só mantinha compromisso com a própria letra" (TATIT, 2004, p.229).

Assim, ao mesmo tempo em que, nas cenas que constroem, as três canções analisadas dão recados aos pais (dos enunciadores), para nós elas deixam recados que refletem as mudanças nas relações familiares e nos comportamentos em nossa sociedade. Por outro lado, também exemplificam distintos modos de cantar, de compor e de tratar a relação entre melodia e letra - ou seja, expressam diferentes dicções presentes na canção popular brasileira.

\section{Referências}

CAVALCANTI, Senyra Martins; MELO, Rosemary Alves de. 0 reality show "SuperNanny": a educação infantil na lógica da polícia da família. João Pessoa: Conferência Internacional Educação, Globalização e Cidadania, 2008. Digitado. (Trabalho apresentado em mesa redonda)

GIDDENS, Anthony. Sociologia. 4. ed. Porto Alegre: Artmed, 2005.

LÉVI-STRAUSS, Claude. A família. In: LÉVI-STRAUSS, Claude; GOUGH, Kathleen; SPIRO, Melford. A familia: origem e evolução. Porto Alegre: Vila Martha, 1980. p.7-45.

MAINGUENEAU, Dominique. Elementos de linguística para o texto literário. São Paulo: Martins Fontes, 1996.

PENNA, Maura. Diálogos entre filhos(as) e pais em canções populares brasileiras. In: COLÓQUIO CIDADANIA CULTURAL, 2009, Campina Grande. In: Colóquio Cidadania Cultural: diálogo de gerações nas narrativas modernas; livro de resumos. Campina Grande: MLI/UEPB, 2009. p.91.

TATIT, Luiz. A canção: eficácia e encanto. São Paulo: Atual, 1986.

. O cancionista: composição de canções no Brasil. 2. ed. São Paulo: EDUSP, 2002.

O século da canção. Cotia/SP: Ateliê, 2004.

THERBORN, Göran. Sexo e poder: a família no mundo. São Paulo: Contexto, 2006.

VALADARES, Ricardo. Acima do bem e do mal. Veja, edição 1891, 9 fev. 2005, p.58-65. Disponível em: http://veja.abril. com.br/acervodigital/home.aspx Acesso em: 12 set. 2009.

VALVERDE, Monclar. Mistérios e encantos da canção. In: MATOS, Cláudia Neiva de; TRAVASSOS, Elizabeth; MEDEIROS, Fernanda Teixeira de (Orgs.). Palavra cantada: ensaios sobre poesia, música e voz. Rio de Janeiro: 7Letras, 2008. p.268-277.

VIORST, Judith. Perdas necessárias. 19. ed. São Paulo: Melhoramentos, 1999.

ZUMTHOR, Paul. Performance, recepção, leitura. São Paulo: Cosac Naify, 2007. 


\section{Referências sonoras}

BITTENCOURT, Sérgio. Naquela mesa. (intérprete: Nelson Gonçalves). In: FAOUR, Rodrigo (Org.). Como nossos pais. Rio de Janeiro: Som Livre, 2008. CD. faixa 9.

CARVALHO, Roberto de; LEE, Rita. Papai me empresta o carro (intérprete: Rita Lee). In: FAOUR, Rodrigo (Org.). Como nossos pais. Rio de Janeiro: Som Livre, 2008. CD. faixa 6.

FÁBIO Jr. Pai. (intérprete: Fábio Jr.) In: FAOUR, Rodrigo (Org.). Como nossos pais. Rio de Janeiro: Som Livre, 2008. CD. faixa 8.

FAOUR, Rodrigo (Org.). Como nossos pais. Rio de Janeiro: Som Livre, 2008. CD.

LIMA, Marina; CíCERO, Antônio. Já fui (intérprete: Marina Lima) In: FAOUR, Rodrigo (Org.). Como nossos pais. Rio de Janeiro: Som Livre, 2008. CD. faixa 7.

\section{Notas}

Este texto apresenta uma versão revista e ampliada de PENNA (2009). Agradecemos à Profa. Eurides Santos e aos Profs. Carlos Sandroni e Luis Ricardo Silva Queiroz pela sua leitura crítica e valiosas contribuições para o processo de reelaboração.

1 "O próprio registro autoral de uma composição incide sobre os versos e o contorno melódico emitidos pela voz do cantor." (TATIT, 1986, p.1)

2 Conforme biografia de Rodrigo Faour, disponivel em: http://rodrigofaour.com.br/quem-e-rodrigo-faour. Acesso em: 13 set. 2009.

3 Conforme informações disponiveis em: http://rodrigofaour.com.br/cats/discos/coletaneas Acesso em: 13 set. 2009.

4 Disponivel em: http://rodrigofaour.com.br/cats/discos/coletaneas Acesso em: 13 set. 2009.

5 De acordo com o Dicionário eletrônico Houaiss da língua portuguesa.

6 Conforme informações disponiveis em: http://pt.wikipedia.org/wiki/Com_Licença,_Eu_Vou_à_Luta Acesso em: 13 set. 2009.

7 Como mostra TATIT (1986, p.60), há os protótipos de canções que exploram predominantemente cada um dos processos: figurativização, tematização e passionalização (ver tb. TATIT, 2002, p.26 - sobre a arquicanção como canção-modelo). No entanto, usualmente, cada canção faz uso dos três processos, sendo por vezes dificil identificar qual deles é predominante.

Maura Penna é Doutora em Linguística pela Universidade Federal de Pernambuco, Mestre em Ciências Sociais pela Universidade Federal da Paraiba, Graduada em Música (licenciatura e bacharelado) e Educação Artística pela Universidade de Brasília. Atualmente é Professora Adjunto I do Departamento de Educação Musical da Universidade Federal da Paraíba. Tem experiência na área de Música, Arte e Educação, Estudos Culturais, com ênfase em Educação Musical, atuando principalmente nos seguintes temas: educação musical, política educacional para arte e música, prática pedagógica em música, pesquisa em educação, além de manifestações culturais e artísticas na contemporaneidade - especialmente música popular e midiática. É autora de Música(s) e seu ensino (Sulina, 2008), entre outras obras já esgotadas, e de inúmeros artigos publicados em coletâneas, periódicos científicos e anais de congressos. 